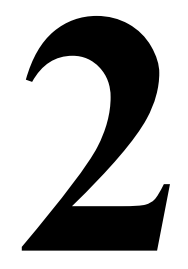

\title{
A IMPORTÂNCIA DO PROGRAMA SAÚDE NA ESCOLA NO RETORNO DAS AULAS PRESENCIAIS APÓS A PANDEMIA DE CORONAVÍRUS
}

\author{
- Alan Santiago Muri Gama ${ }^{I}$ \\ - Elizabeth Almeida da Silveira Santiago ${ }^{1}$ \\ - Evan Pereira Barreto ${ }^{I}$ \\ - Kleyton Corrêa Borges ${ }^{1}$ \\ - Luciano Ribeiro Helvécio ${ }^{I}$ \\ - Luís Carlos Bicalho de Lima ${ }^{1}$ \\ - Marcus Vinícius Pena Abranches Pachecoa ${ }^{I}$ \\ - Mellina da Silva Gonçalves ${ }^{1}$ \\ - Rita Maria Fernandes Leal Moreira Cacemiro ${ }^{I}$
}

\section{INTRODUÇÃO}

A escola historicamente foi reconhecida como ambiente para se promover educação e disseminar os conhecimentos científicos acerca das áreas mais importantes para o desenvolvimento humano. No século passado a educação e a saúde caminharam juntas, o Ministério da Educação também era o Ministério da Saúde, e políticas públicas eram desenvolvidas em conjunto para ambas as áreas.

Para Silva e colaboradores (2010), a relação entre educação, saúde e suas práticas é condicionada por complexas dimensões estruturais que requerem análise histórica para melhor compreensão. Historicamente, a sucessão de modelos educacionais usados no campo da saúde pública não representa uma sequência evolutiva; antes, é uma descrição da prática dominante em determinados momentos em relação aos problemas de saúde destacados em uma intervenção para manter o domínio da classe dominante. Parece, portanto, que as ações desenvolvidas foram e continuam a ser norteadas pelas concepções de saúde e educação em saúde de cada período histórico e pelos modelos de atenção implantados nos serviços de preservação da saúde dos trabalhadores.

Tornar Saúde e Educação direitos fundamentais foi uma das tarefas de maior responsabilidade do legislador original. É dever do Estado garantir à todos, independentemente de qualquer diferença, que haja saúde e educação para todos. Colocar essas áreas para caminhar em conjunto, foi uma forma de buscar atender as necessidades sociais em situações em que uma dependa da outra. A saúde na escola é uma política que

1 Faculdade Vale do Cricaré (FVC) - São Mateus, ES. E-mail: 
busca prevenir doenças no futuro, e dessa forma, trabalha desde de tenra idade as necessidades e cuidados para que não haja adoecimentos.

O Programa Saúde na Escola (PSE) é uma estratégia que integra atividades educacionais e de saúde com o objetivo contribuir para a formação integral dos alunos em rede pública de ensino fundamental por meio de ações preventivas, promocionais e de saúde. O PSE também é um apoiador de fortalecimentos das atividades no campo e da articulação da saúde e educação, buscando enfrentar as fragilidades que ameaçam esses grupos da população. Portanto, deve ser implementado com a participação efetiva das equipes da ESF, integração com uma escola do mesmo território, cumprimento das normas do SUS (BRASIL et al., 2017).

$\mathrm{Na}$ busca por atender as demandas da saúde do alunado brasileiro, em 2007 foi lançado pelo governo federal o PSE, que com a finalidade de cuidar da saúde dos alunos na primeira infância se desdobrou por diversas áreas com a finalidade de incentivar os primeiros cuidados com a saúde. Atuando em diversos campos, o PSE atua desde a saúde bucal, passando pela saúde alimentar até a saúde mental. No campo da saúde mental, importa ressaltar suas políticas e como elas serão necessárias aos cuidados após a Pandemia de Coronavírus (COVID-19) que desencadeou um enorme isolamento social desde o início do ano de 2020.

A pandemia de COVID-19 causada pelo novo Coronavírus (SARS-CoV-2) provou ser um dos maiores desafios de saúde global deste século. No meio do mês de abril, poucos meses após o surto na China no final de 2019, já haviam acontecido mais de 2 milhões de casos e 120.000 mortes em todo o mundo por COVID-19 e há muitos casos e mortes são esperados nos próximos meses. Na época, no Brasil, o COVID-19 havia registrado cerca de 21.000 casos confirmados e 1.200 óbitos. Até o mês de agosto, o Brasil se aproxima da marca de 120.000 mortes e ultrapassa a marca de 3 milhões de infectados (WERNECK; CARVALHO, 2020).

O Conhecimento científico insuficiente sobre o novo coronavírus, sua alta velocidade a disseminação e a possibilidade de causar a morte em populações vulneráveis geram incertezas quanto às melhores estratégias para combater a epidemia em diferentes partes do mundo. No Brasil, os desafios são ainda maiores, tão pouco se sabe sobre as características de transmissão do COVID-19 no contexto altas desigualdades sociais, com populações vivendo em condições precárias de moradia e sanitárias, sem acesso constante a água e em caso de aglomeração (WERNECK; CARVALHO, 2020).

Entretanto, de todas as estratégias desenvolvidas para conter a pandemia, a melhor de todas foi evitar o alto índice de contaminação para que os sistemas de saúde pudessem se equipar e não desencadear uma onda de colapsos nos sistemas. O Sistema Único de Saúde (SUS) brasileiro conseguiu evitar o colapso, mas teve que lidar com situações calamitosas quanto ao número de leitos em Unidades de Terapia Intensivas (UTIs).

$\mathrm{O}$ isolamento social fez com que muitos serviços essenciais fossem paralisados, somente serviços médicos e referentes a alimentação da população que não sofreram nenhum bloqueio. A educação foi totalmente paralisada nos primeiros meses e posteriormente retornou na modalidade à distância (EAD). Muito se trabalhou no sentido de cuidar para que a educação não fosse prejudicada, entretanto pouco se falou da saúde mental dos alunos e dos professores, quais as possíveis influências que aulas em EAD podem causar nesse campo da saúde e como que o distanciamento social pode promover alterações no cotidiano dos atores da vida escolar.

Nesse quesito, o Brasil tem seguido a tendência mundial. Em todo o território nacional, redes públicas e 
privadas interromperam o funcionamento das escolas e, entre outras ações, têm cogitado - ou já estão em processo de - transferir aulas e outras atividades pedagógicas para formatos a distância. Por ora, são as redes estaduais que mais têm avançado nesse sentido, e o caminho tem sido viabilizado, principalmente, por meio da disponibilização de plataformas online, aulas ao vivo em redes sociais e envio de materiais digitais aos alunos, como mostra recente levantamento realizado com mais de três mil Secretarias de Educação de todo o País (BRASIL, 2020, s/p).

Por isso, a importância de se valorizar o PSE, para que após a Pandemia seja uma válvula de escape para tratar os novos problemas que poderão surgir e cuidar para que novas doenças como o Coronavírus possam ser evitadas.

É objetivo deste estudo apresentar como que o Programa Saúde na Escola (PSE) pode atuar no retorno das aulas presenciais após a pandemia do novo Coronavírus, e quais as novas possíveis demandas que podem ser investidas para evitar que transtornos acometam os discentes e docentes. Também é objetivo deste artigo evidenciar quais os desafios no retorno das aulas após a pandemia no sentido de instruir a comunidade escolar a se prevenir e buscar métodos de evitar o surgimento de novas doenças.

\section{DESAFIOS NO RETORNO DAS AULAS PRESENCIAIS NO PÓS PANDEMIA}

De acordo com a Organização das Nações Unidas para a Educação, a Ciência e a Cultura (UNESCO, 2020), 186 países ou regiões fecharam escolas, total ou parcialmente, no início de maio de 2020 para conter a disseminação do Covid-19, atingindo cerca de 70\% dos alunos. Este fechamento afetou o calendário escolar e seu impacto na aprendizagem dos alunos é incerto. As diferenças no rigor da quarentena, na duração e nas estratégias adotadas pelas famílias e escolas são apenas alguns dos fatores que podem influenciar a trajetória desses alunos.

Em meio à atual pandemia, a ciência, apoiada em evidências empíricas, ganhou importância irrefutável. Portanto, compreender o impacto da Covid-19 na educação, com base no que dizem as evidências científicas, é importante para a sociedade. Nesse contexto, o objetivo deste artigo é examinar o impacto do fechamento de escolas no desempenho dos alunos no curto prazo e em suas trajetórias de longo prazo. Também visa refletir sobre as potenciais intervenções de curto prazo que poderiam mitigar suas consequências. Em alguns casos, por lacuna literária ou tempo de publicação insuficiente, foram investigados artigos científicos que ainda não haviam sido publicados, sempre obedecendo a critérios de disciplina científica (OLIVEIRA et al., 2020).

Tornar o ambiente escolar um foco de pesquisa disseminador de boas e novas ações, sempre foi o objetivo central de tornar a educação democratizada. Desde que a escola deixou de ser um ambiente para os filhos dos mais ricos e passou a receber pessoas de todas as camadas sociais, a escola não foi inovada e os métodos se mantiveram os mesmos, o que dificultou a atividade de dar a cada aluno a assistência que cada um precisa.

Na opinião de Dias e Pinto (2020), quando as escolas forem reabertas, e em algumas partes do mundo esse evento já tiver começou, a recessão econômica que se seguirá certamente aumentará as desigualdades e poderá reverter o progresso de alguns países no aumento do acesso à educação e na melhoria do aprendiza- 
do. Portanto, é preciso que os países reconheçam o problema - o que não acontecia quando a COVID-19 começou a se espalhar pelo mundo - e criem políticas públicas voltadas especificamente para a educação.

Buscando inovar e propor novas técnicas, foi imprescindível respeitar a individualidade humana e trabalhar novas formas de introduzir os conceitos educacionais. Para justificar estes dados ao objetivo desta pesquisa, basta conectar a necessidade de integrar a grade educacional com novos métodos para propor melhores ações e maiores cuidados no combate de doenças, e garantir que os alunos estejam preparados para novas práticas após o retorno à sociedade, ao fim ou controle da pandemia.

[...] por mais que a economia dos países sofra com a pandemia, os investimentos em Educação devem ser mantidos, quiçá aumentados. Conforme a Unesco, a natural queda na aprendizagem poderá alastrar-se por mais de uma década se não forem criadas políticas públicas que invistam em melhorias de infraestrutura, tecnologias, formação, metodologias e salários, além do reforço da merenda, melhor aproveitamento do tempo, tutoria fora do horário usual das aulas e material adicional, quando possível (UNESCO, 2020, p.14).

A realidade social dos alunos é diversa, e garantir que cada aluno possua os recursos necessários para adotar as novas práticas é um outro desafio. Essas novas práticas são: uso de máscaras; adotar novas práticas de higiene corporal; novas políticas de contato físico e novas práticas alimentares (sejam elas para evitar contato com doenças ou para adquirir imunidade). Também importa considerar o incentivo aos cuidados com o meio ambiente e o desenvolvimento do conhecimento científico na área, para que no futuro o número de pesquisadores seja mais volumoso e de melhor qualidade.

As condições sociais são as raízes da precariedade da saúde e do surgimento da doença, na proposição dessa teoria, na determinação do acesso a recursos importantes que podem ser usados para evitar riscos ou minimizar as consequências das doenças, e quando afetam muitos desfechos de saúde por meio de vários mecanismos. A natureza flexível e multifuncional dos recursos econômicos e sociais significa que podem ser usados de diferentes maneiras em diferentes situações para promover a saúde de seus proprietários ou minimizar os efeitos da doença quando ela ocorre (SANTOS, 2020).

\footnotetext{
No contexto de um sistema dinâmico de mudanças nas doenças, tratamentos, riscos e fatores de proteção, a associação geral entre as condições sociais e a distribuição da saúde se reproduz no tempo por meio da transposição das vantagens em recursos de uma situação para a outra e por meio de processos socialmente seletivos de substituição dos mecanismos mediadores mais próximos na cadeia causal que leva à saúde e à doença. Quando as pessoas usam recursos para proteger ou promover a saúde, isto se dá no contexto de um sistema estruturalmente desigual. As disparidades de saúde são alimentadas como consequência da própria expansão social da capacidade de controlar as condições de saúde. As desigualdades sociais e econômicas existentes fazem com que o benefício da nova capacidade desenvolvida seja apropriado com maior sucesso por aqueles segmentos da população que possuem mais recursos, informações e oportunidades (SANTOS, 2020, p.5).
}

Retornar às aulas e cobrar do corpo discente todas essas novas práticas será um desafio não apenas para os alunos, mas para o próprio corpo docente que terá que adotar essas novas práticas a fim de exemplificar e também tomar os devidos cuidados.

Atentos a questão ambiental, Troi e Quintilio (2020), apontaram que a presença do vírus em nosso dia a dia trouxe mudanças radicais na maneira como vivemos. Primeiro na China e depois na Itália, onde a redução da poluição na área afetada foi registrada pela comparação de imagens de satélite. Com isso, 
foi demonstrado que a atividade humana tem impacto e que as operações de emergência global seriam possíveis para reduzir as emissões de gases de efeito estufa, proporcionando um planeta menos aquecido. Também evitaria o surgimento de novas epidemias devido à miríade de vírus que poderiam congelar no chamado permafrost, solos congelados por milhares de anos, e até mesmo organismos virais que ainda se escondem nos remanescentes florestais destruídos pela força do agronegócio.

A questão ambiental pode estar intimamente ligada ao surgimento da nova pandemia, o que traz a necessidade de influenciar as políticas ambientais em sala de aula e desenvolver essa área do conhecimento. Os veículos de comunicação divulgaram os dados fornecidos por pesquisas que foram chanceladas pela Organização Mundial da Saúde (OMS) indicando a mutação no vírus em algumas espécies animais, o que remete aos cuidados no consumo de carne e como a extinção de algumas espécies pode aumentar a proliferação de agentes transmissores de doenças.

Bactérias e vírus são velhos conhecidos. Tudo indica que o modo de vida de nossos ancestrais caçadores-coletores, que percorriam a Terra em pequenos grupos, não era propício à formação da epidemia. Após nossa fixação, passamos muito tempo sobrevivendo e criando resistência imunológica a essas estruturas incríveis que habitavam o planeta antes mesmo de nossa existência. Não demorou muito: não tinha mais de 12.000 anos quando começaram as residências permanentes humanas. Foi só em 1647 que Anton Van Leeuwenhoek foi capaz de ver, sob um microscópio, "criaturas minúsculas" caseiras em uma gota d'água pela primeira vez. Nos próximos 300 anos, encontramos muitas outras espécies microscópicas (HARARI, 2015).

Transmitir a importância de se conhecer a origem do vírus, e como a influência sobre o tratamento do meio ambiente age no combate a proliferação de doenças e no evitar do surgimento de novas doenças, faz com que as gerações futuras estejam cada vez mais conscientes das suas responsabilidades, e é através do ambiente escolar que se dissemina os objetivos para o futuro, já que é nele que estão as futuras gerações e é através delas que se promove alterações sociais a longo prazo.

\section{POLÍTICAS DE SAÚDE MENTALATRAVÉS DO PROGRAMA SAÚDE NA ESCOLA (PSE)}

A relação entre saúde / doença mental e sensibilidade social é muito complexa e requer muita reflexão e contextualização para ser compreendida de uma forma que não reproduza a lógica simplificada que liga "loucura" e "pobreza", reforçando estigma e preconceitos em relação aos menos favorecidos população. Ao mesmo tempo, a problematização dessa questão pode indicar os rumos de boas práticas na área da saúde mental (GAMA et al., 2014).

As doenças mentais são entendidas como distúrbios da trajetória de vida decorrentes de alterações no desenvolvimento neurológico e que se manifestam na infância. Essa perspectiva enfatiza o papel da escola enquanto os professores e a família não só lidam com a questão da aprendizagem, mas têm uma posição privilegiada, pois ao se tornar obrigatória para todas as crianças e adolescentes brasileiros, esse ambiente tornou-se um local privilegiado de alta concentração de estimulação longitudinal e de grande impacto em todos os aspectos da vida (GARCIA, 2016). 
O Programa Saúde na Escola (PSE) lançado pelo governo federal no ano de 2007 atua em diversos campos da saúde discente. O objetivo é combater doenças e identificar morbidades que costumam aparecer na infância e na adolescência. Também trabalha questões alimentares através dos programas nutricionais, a saúde bucal e desdobra-se para questões referentes a saúde mental, na identificação e no tratamento de transtornos. De acordo com pesquisas realizadas por Cid MFB, et al. (2019), os resultados de estudos epidemiológicos indicam que de 10 a $25 \%$ das crianças e jovens no Brasil e no mundo vivenciam sofrimento mental. Estes dados é importante porque é uma condição que envolve perdas em desenvolvimento e suas vidas, bem como aqueles com quem vivem.

A eficácia da saúde escolar como política pública de promoção da saúde e seguro de qualidade de vida requer coordenação e planejamento intersetorial definição de iniciativas interdisciplinares selecionado do diagnóstico local da realidade, identificação do problema e soluções reais. A política de saúde reconhece que o espaço escolar é um ambiente fértil privilegiado para a divulgação e realização de práticas pró-saúde, ações preventivas e educação em saúde (FONTENELE et al., 2017).

No contexto da prevenção da saúde, certas medidas são tomadas para proteger a comunidade do risco de doenças transmissíveis. Distância social ou física significa manter uma distância espacial - cerca de dois metros - entre uma pessoa e outras pessoas quando elas estão fora de casa. Isso resulta, por exemplo, em uma recomendação de não se reunir em grupos e evitar locais lotados e aglomerados. É uma medida implementada pelos países para evitar a contaminação.

A preocupação com a saúde mental da população se intensifica durante a grave crise social. A pandemia de coronavírus 2019 (COVID-19) pode ser descrita como uma daquelas crises que tem se caracterizado como um dos maiores problemas de saúde pública internacional das últimas décadas, afetando praticamente todo o planeta. Tal evento causa distúrbios psicológicos e sociais que afetam a capacidade de enfrentamento de toda a sociedade, de gravidade e extensão variáveis. São necessários esforços notáveis de várias áreas do conhecimento - incluindo a psicologia - para propor formas de lidar com o contexto que permeia a crise (FARO A, et al., 2020).

Com o surgimento da pandemia do novo Coronavírus, foi possível identificar uma série de adoecimentos mentais que foram potencializados pelo isolamento social e pela ausência de interação social. A sociedade não passava por um período parecido desde o século XX, quando no final da década de 10 surgiu a Gripe Espanhola, que ceifou aproximadamente 50 milhões de vidas.

Apesar dos benefícios que traz na contenção da doença, a quarentena costuma estar associada a situações desagradáveis que podem afetar a saúde mental dos envolvidos. Alguns dos fatores de estresse na quarentena são: a necessidade de se separar de amigos e familiares, incerteza sobre distâncias, medo, tédio e muito mais. Estudos conduzidos em situações de pandemia como COVID-19 e SARS descobriram que a quarentena pode desencadear alguns transtornos mentais comuns, como transtornos de ansiedade e depressão, e sinais de aumento do comportamento suicida (FARO et al., 2020).

Doenças como a depressão, transtornos de pânico além de ausência de interação, que pode ser considerada um movimento contrário às práticas saudáveis humanas, deverão ser observadas com maior atenção, pois o agravo dessas doenças pode levar a continuidade da mortalidade em decorrência do surgimento do novo Coronavírus, o que indica que não é só pela infecção pela doença que o vírus faz vítimas.

Como forma de enfrentar esse processo e fornecer auxílio, foi desenvolvida uma cartilha baseada em táticas de enfrentamento ao adoecimento mental em tempos de isolamento social. A cartilha base para o 
enfrentamento do estresse em resposta a uma pandemia é um produto intersetorial do grupo de trabalho PsiCOVIDa. A pesquisa é formada por dois psicólogos e três estudantes de graduação em psicologia da PUCRS e da PUC-Campinas, buscando popularizar o conhecimento científico sobre o estresse e sua Resposta.

As respostas voluntárias e involuntárias de estresse e ansiedade podem ter resultados adaptativos ou mal adaptativos na saúde física e mental. Com esse enfoque, a cartilha ajuda a reconhecer sinais de estresse e ansiedade, e informa possíveis estratégias de enfrentamento frente às mudanças na rotina, aos protocolos de distanciamento social, à sobrecarga de notícias por vezes conflitantes, e às incertezas sociopolíticas e econômicas (LUNN et al., 2020, p. 11).

Retirar a criança e adolescente do convívio social pode ter consequências muito maiores que as esperadas, já que viver em sociedade faz parte de um movimento importante para o desenvolvimento intelectual. Estar em sociedade é amadurecer os desejos humano e coletar informações que colaborar para a formação física e intelectual.

O PSE reforça no decorrer dos anos suas políticas ligadas a saúde mental. Muitos projetos, um com aprovação recente, buscam inserir psicólogos no cotidiano escolar, em toda rede pública de ensino brasileira. A ideia gira em torno de identificar possíveis transtornos na vida dos alunos e também uma forma de evita-los através de instruções que não podem ser passadas pelas famílias.

Para Coutinho e et al. (2015), garantir o desempenho do psicólogo formador em contextos escolares/ educativos exige a reflexão sobre uma prática há muito discutida e imbuída dos desafios colocados a cada processo formativo. A visão geral da gênese e desenvolvimento da psicologia escolar, inicialmente tinha o compromisso ou intenção de promover o bem-estar e o desenvolvimento saudável das crianças em idade escolar em uma discussão mais ampla. Em uma sociedade capitalista, em defesa das diferenças individuais, é necessária uma ciência que examine o indivíduo como tal, isolado de seu contexto e responsável por aproveitar as mesmas oportunidades para todos. Nesse cenário, a psicologia se apresentou como uma ciência não histórica capaz de cumprir essa promessa.

\section{CONSIDERAÇÕES FINAIS}

Com base no conhecimento adquirido e nos materiais colhidos e desenvolvidos nesta pesquisa, pode-se concluir que o Programa Saúde na Escola (PSE) desenvolve muito mais que um papel de política pública de saúde, em conjunto com a educação, na identificação de adoecimentos precoces, mas também atua no combate de doenças e no tratamento de novos adoecimentos, como os que podem surgir em decorrência do isolamento social na pandemia do novo Coronavírus.

É importante atentar para os novos desafios que virão após o fim do isolamento social, já que a sociedade a qual foi deixada antes da Pandemia, não será mais encontrada no retorno, já que novos hábitos e práticas deverão ser desenvolvidos e as instruções para que essas novas práticas imperem devem partir da escola, que é ambiente científico de ensino.

Garantir que essas práticas sejam desenvolvidas e adotadas socialmente requer zelo e sensibilidade para a realidade social. O Brasil é um País que aporta um alto índice de desigualdade, que depende amplamente 
da figura de um Estado atuante, que propõe e executa políticas públicas. A inevitável crise econômica que surgirá após a pandemia em decorrência do freio dado durante o isolamento, pode comprometer programas que sustentam boa parte da população brasileira, e é imprescindível que os atores responsáveis pelo Estado estejam atentos para não sacrificarem as classes menos favorecidas.

Garantir novas políticas educacionais e de saúde, principalmente as que caminham em conjunto, será o caminho para dar continuidade ao que apregoa o Artigo $3^{\circ}$ da Constituição Federal (1988), que diz "Constituem objetivos fundamentais da República Federativa do Brasil: [...]erradicar a pobreza e a marginalização e reduzir as desigualdades sociais e regionais;”. 


\section{REFERÊNCIAS BIBLIOGRÁFICAS}

BRASIL. 1988. Constituição da República Federativa do Brasil. Brasília; 2 ed. 1990.

BRASIL. 2020. In: Nota técnica ENSINO A DISTÂNCIA NA EDUCAÇÃO BÁSICA FRENTE À PANDEMIA

DA COVID-19: Brasília. Disponível em: https://www.todospelaeducacao.org.br/_uploads/_posts/425.pdf. Acesso em: 14 de ago. 2020.

BRASIL EGM, et al. Promoção da saúde de adolescentes e Programa Saúde na Escola: complexidade na articulação saúde e educação. Rev Esc Enferm USP, 2017; 51(1): 1-9.

CID MFB, et al. Saúde mental infantil e contexto escolar: as percepções dos educadores. Pro-posições, 2019; 30(1): $1-24$.

COUTINHO AFJ, et al. A psicologia na escola - (re)pensando as práticas pedagógicas. Psicologia da Educação, 2015; 40(1): 103-114.

DIAS E, PINTO FCF. A Educação e a Covid-19. Ensaio: Avaliação e Políticas Públicas em Educação, 2020; 28(108); 545-554.

FARO A, et al. COVID-19 e saúde mental: a emergência do cuidado. Estudos de Psicologia (Campinas), 2020; 37(1): 1-19.

FONTENELE RM, et al. Construção e validação participativa do modelo lógico do Programa Saúde na Escola. Saúde e Debate, 2017; 41(1): 167-179.

GAMA CAP, et al. Saúde mental e vulnerabilidade social: a direção do tratamento. Revista Latinoamericana de Psicopatologia Fundamental, 2014; 17(1): 69-84.

GARCIA JM. Saúde Mental na Escola: O que os Educadores Devem Saber. Psico-USF, 2016; 21(2): 423-425.

HARARI YN. Sapiens - uma breve história da humanidade. Porto Alegre: L \& PM, 2015.

Lunn P, et al. Using behavioural science to help fight the coronavirus. ESRI Working Paper, 2020; ${ }^{\circ}$ 656. Dublin: Behavioural Research Unit, Economic and Social Research Institute. Retrieved from:

OLIVEIRA JBA, et al. A Covid-19 e a volta às aulas: ouvindo as evidências. Ensaio: Avaliação e Políticas Públicas em Educação, 2020; 28(108): 555-578.

SANTOS JAF. Covid-19, causas fundamentais,classe social e território. Trabalho, Educação e Saúde, 2020; 18(3): 1-11.

SILVA CMC, et al. Educação em saúde: uma reflexão histórica de suas práticas. Ciência \& Saúde Coletiva, 2010; 15(5): 2539-2550.

TROI M, QUINTILIO W. Coronavírus: lições anti-negacionistas e o futuro do planeta. Scielo em Perspectiva, 2020.

UNESCO. COVID-19 impact on education. Disponível em: https://en.unesco.org/covid19/educationresponse. Acesso em: 16 de ago. 2020.

WERNECK GL, CARVALHO MS. A pandemia de COVID-19 no Brasil: crônica de uma crise sanitária anunciada. Cad. Saúde Pública, 2020; 36(5): 1-4. 